\title{
The effect of calcining temperature on the properties of 0-3 piezoelectric composites of PZT and a liquid crystalline thermosetting polymer
}

\author{
Daan A. van den Ende • Wilhelm A. Groen • \\ Sybrand van der Zwaag
}

Received: 29 August 2008 / Accepted: 18 April 2010/Published online: 9 May 2010

(C) The Author(s) 2010. This article is published with open access at Springerlink.com

\begin{abstract}
We report on the optimisation of a recently developed high performance 0-3 piezoelectric composite comprising of the piezoelectric Lead Zirconate Titanate (PZT) powder and a liquid crystalline thermosetting matrix polymer (LCT). The matrix polymer is a liquid crystalline polymer comprising of an HBA-HNA backbone with phenylethynyl end-groups. The use of a high performance polymer makes the composite a possible candidate to be used in sensor applications at elevated temperatures. The composite properties were optimised by calcining the PZT powder at different temperatures, prior to mixing the powders into the LCT matrix. The aim is to study the effect of the calcining temperature on the piezoelectric properties of the composite The PZT powders were characterised by X-ray diffraction and scanning electron microscopy. The dielectric constant and piezoelectric charge constant $\left(d_{33}\right)$ of the composite samples was measured. It was found that a relationship exists between the calcining temperature of the PZT powder and the piezoelectric properties of the composites. A maximum voltage constant of $g_{33}=63 \mathrm{mVm} / \mathrm{N}$ was obtained for a composite containing $40 \%$ (by volume) of PZT powder calcined at $1150^{\circ} \mathrm{C}$.
\end{abstract}

Originally presented at Electroceramics XI, Manchester, UK, 2008

D. A. van den Ende $(\bowtie) \cdot$ W. A. Groen

Department of Materials Technology, TNO Science \& Industry,

Rondom 1,

5612AP Eindhoven, The Netherlands

e-mail: Daan.vandenende@tno.nl

URL: www.tno.nl

D. A. van den Ende - W. A. Groen - S. van der Zwaag

Novel Aerospace Materials Group, Faculty of Aerospace

Engineering, Delft University of Technology,

Kluyverweg 1,

2629 HS Delft, The Netherlands
Keywords Piezoelectric composite $\cdot$ PZT . Calcining temperature

\section{Introduction}

Lead Zirconate Titanate (PZT) ceramics can be used as sensors for in-situ health monitoring systems for structural systems, such as vibration monitoring, acoustic emission detection and impact detection [1]. Especially in aerospace fibre composite structures, such systems are important for detection of oncoming failure of the component. However, the use of PZT ceramics often leads to difficulties, due to a poor compatibility with composite processing and the low fracture toughness of the ceramic material. In contrast piezoelectric ceramic-polymer composite materials offer a way to incorporate the sensor function into a fibre reinforced composite, while retaining a relatively flexible material that is more easily compatible with composite processing techniques. Especially integrated piezoelectric sensors can be realised with 0-3 type composites, consisting of a PZT particulate phase and a high performance polymer as a matrix phase (using the terminology defined by Newnham et al. [2]).

The use of piezoelectric 0-3 composites for sensor applications has been extensively researched for a number of different polymer systems [3-12]. For this type of composite, mainly the thermoplastic ferroelectric polymer, poly-vinylidenefluoride (PVDF) [3-10] and thermosetting epoxy based resins [11, 12] were used. In many of these studies, the PZT powder was a commercial PZT powder. In other cases, the researchers simply state the use of "PZT powder". However, in many cases the properties of PZT powder will be different from PZT ceramic products obtained by sintering. During sintering of PZT ceramics, phase formation and particle size growth will generally enhance the piezoelectric properties of the PZT 
material. Commercial powders in particular are not single phase powders and composites made from these powders will therefore not exhibit optimal properties.

High Curie temperature PZT can be used as a sensor material at elevated temperatures, for instance in certain aerospace applications. For composites, use at higher temperatures is generally limited by the properties of the polymer matrix phase. The decreasing mechanical and electrical properties of the matrix compromise the performance of the sensor at high temperatures and rapid matrix degradation will limit the lifetime of the sensor. It is then necessary to use high performance polymers with much better temperature stability [13]. A class of these polymers are aryl terminated thermosetting polymers, such the liquid crystalline polyester thermoset (LCT). This class of LCT polymers comprise of an HBA-HNA backbone with phenylethynyl end-groups, which was used as a matrix polymer in this research. The LCT type thermoset polymers are obtained by thermal curing of thermotropic liquid crystalline oligomer systems, in which thermally reactive end groups terminate the oligomers. Before curing the oligomeric resin has a low melt viscosity and behaves as a thermoplastic resin. When the resin is heated over $300^{\circ} \mathrm{C}$ the reactive end groups will react and form a network. Due to the all aryl polymer backbone and its liquid crystalline nature the LCT has excellent high temperature properties and excellent chemical resistance. The low viscosity and its good bonding characteristics yield an excellent processability. The polymer chemistry and its processing properties are presented in [14]. In previous work, a composite of PZT and the polymer was developed, as a piezoelectric composite which is useable in high temperature applications (up to $200^{\circ} \mathrm{C}$ ). A first presentation of the PZTLCT composite is given in [15]. It was shown that further calcining the PZT powder influenced the piezoelectric properties of the composite material. In the present study the aim is to achieve an increase in piezoelectric properties of the PZT-LCT composite by calcining the PZT powder at temperatures up to the sintering temperature of PZT ceramics.

\section{Experimental method}

The as received PZT powder (Morgan Electro Ceramics, Ruabon, UK) is a Niobium doped PZT powder with a $\mathrm{Zr} / \mathrm{Ti}$ molar ratio of $52 / 48$, which has been processed at $800^{\circ} \mathrm{C}$. This powder is used for sintering PZT5A4 ceramics. The as received powder was further calcined at temperatures ranging from $900^{\circ} \mathrm{C}$ to $1150^{\circ} \mathrm{C}$. The powders were calcined in a closed Zirconia crucible in air, using a Nabertherm D2804 furnace. The heating rate was set a $5^{\circ} \mathrm{C} / \mathrm{min}$ and the holding time was $1 \mathrm{~h}$, followed by free cooling. The powders were subsequently ball milled in a planetary ball mill (Zirconia milling media), for $8 \mathrm{~h}$ in ethanol to break up agglomerates and achieve particles of similar size distribution. The powders were dried in an air circulating oven at $100^{\circ} \mathrm{C}$ for $24 \mathrm{~h}$ prior to characterisation and mixing in the polymer matrix. The as received powder was also ball milled via the same procedure and was used as a lower reference powder. Furthermore, PZT5A4 ceramic plates (obtained from Morgan Electro Ceramics) were crushed and ball milled for $8 \mathrm{~h}$ in ethanol and used as an upper reference powder for the experiments, as the sintering temperature of these plates was $1200^{\circ} \mathrm{C}$. The powder morphology was characterised by Scanning Electron Microscope (SEM) on a FEI Quanta 600 SEM, operated at $15 \mathrm{kV}$. The phase composition was measured after ball milling by X-ray diffraction (XRD) on a Philips X'pert Pro, $\mathrm{Cu}-\mathrm{K} \alpha 1$ $X$-rays $(\lambda=0,1540562 \mathrm{~nm})$, and particle size by analysis of SEM micrographs, by linear intercept method and elliptical fitting, using the software ImageJ.

All composites contained 40\% PZT powder by volume. Polymer composites were manufactured by pre-mixing the powders in a high shear rotary mixer. The resulting mixture was injection moulded into bars at $270^{\circ} \mathrm{C}$. The uncured composite bar was then divided into samples, which were cured by hot pressing in a mould, capable of containing ten samples. The thickness of the samples obtained by this method was a nominal $200 \mu \mathrm{m}$. The samples were step cured at $300^{\circ} \mathrm{C}$ for $30 \mathrm{~min}$ without applied pressure to relieve the composite of any volatiles still present in the mixture, followed by $340^{\circ} \mathrm{C}$ for $30 \mathrm{~min}$ at $100 \mathrm{kN}$ pressure. The composites were electroded by sputtering a gold layer on the disks (using an Edwards S150B sputtercoater) and poled by applying a d.c. electric field (Heinziger $10 \mathrm{kV} \mathrm{HV}$ generator) to the samples, while monitoring the poling current using a Keithly 175 electrometer. The poling field was set at $15 \mathrm{kV} / \mathrm{mm}$ for $1 \mathrm{~h}$ at a temperature of $180^{\circ} \mathrm{C}$ in silicone oil and samples were left to cool to room temperature before removing the electric field. The dielectric constant was calculated from the capacitance of the composite disks, which was measured on an impedance analyser (HP4194A, operated at $1 \mathrm{~V}, 100 \mathrm{~Hz}$ ). The $d_{33}$ constant was measured on a Berlincourt type $\mathrm{d}_{33}$ meter (KCF Technologies, model PM3001), at room temperature and a fixed frequency of $110 \mathrm{~Hz}$. Per sample type, three samples were measured on five different points on the electroded part of the disk and the average value was calculated.

\section{Results}

\subsection{X-ray diffraction}

The XRD data of the as received powder, the powders calcined at $900^{\circ} \mathrm{C}$ to $1150^{\circ} \mathrm{C}$ and the powder obtained from the sintered ceramic are presented in Fig. 1. The XRD patterns indicate the existence of a perovskite PZT phase. In 
Fig. 1 Diffractograms of PZT powders used for fabricating composites, including the as received powder (AR), powders calcined at $900^{\circ} \mathrm{C}$ to $1150^{\circ} \mathrm{C}$ and powder obtained from a PZT5A4 ceramic sintered at $1200^{\circ} \mathrm{C}$
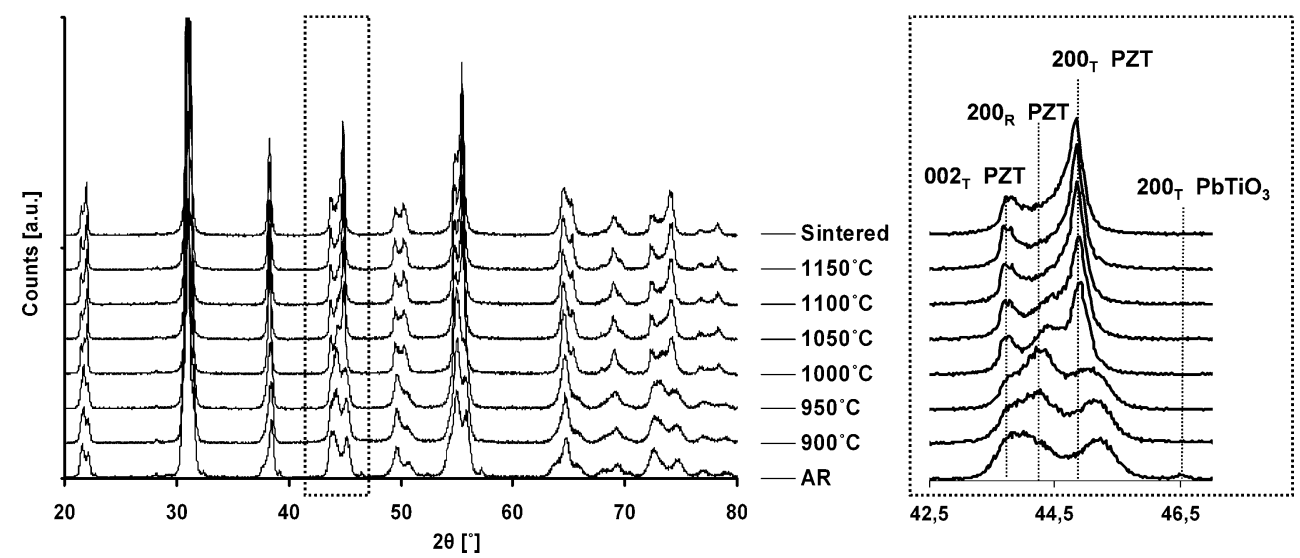

the right inset, a close up of the patterns between $2 \theta$ values of $42.5^{\circ}$ and $47^{\circ}$ is presented. Here, phase coexistence can be observed in several powders.

The as received powder (termed "AR" in Fig. 1) and the powders which were calcined at $900^{\circ} \mathrm{C}$ to $1050^{\circ} \mathrm{C}$ exhibits three peaks between $43^{\circ}$ and $46^{\circ}$, corresponding to multiple phase distributions with varying $\mathrm{Zr} / \mathrm{Ti}$ ratios as both rhombohedral and tetragonal phases are present in these powders [16, 17]. Also, in the as received powder only, a small peak at $46.45^{\circ}$, corresponding to the 200 reflection of tetragonal $\mathrm{PbTiO}_{3}$ phase, is present. In the powder calcined at $1100^{\circ} \mathrm{C}$ and higher, the two split peaks, at $43.7^{\circ}$ and at $44.8^{\circ}$ reveal the existence of a primarily tetragonal phase in the PZT material. A third peak corresponding to a rhombohedral phase is no longer visible between these two peaks. For powders calcined at $1100^{\circ} \mathrm{C}$ and $1150^{\circ} \mathrm{C}$ similar diffractograms are obtained as the diffractogram from the powder from sintered PZT5A4 ceramics.

The Ti content in the tetragonal and rhombohedral phases was calculated from XRD results by the technique outlined in [16]. The average $\mathrm{Ti}$ content (x) in both tetragonal and rhombohedral phases was estimated by comparing with the calculated lattice constants of $\mathrm{Pb}\left(\mathrm{Zr}_{1-\mathrm{x}} \mathrm{Ti}_{\mathrm{x}}\right) \mathrm{O}_{3}$ material, to the average lattice constants derived from the XRD measurements, using the 002 and 200 tetragonal reflections and the 200 rhombohedral reflection (Fig. 2(a)). From these average lattice parameters, the estimated average Ti content (x) of the compositional distributions is calculated using Vegard's law. The estimated average Ti content in the powders as a function of calcining temperature is presented in Fig. 2(b). It must be noted that only the existence of the different phases is confirmed by XRD, the relative volume fraction of both the phases in the powder could not be determined accurately based on the XRD data only.

\subsection{Scanning electron microscopy}

In Fig. 3, secondary electron images (SEI) of the morphology of the PZT powders is presented. The particle size is seen to increase with calcining temperature of the powder. The as received and low temperature calcined particles appear to have a rounder shape than samples calcined at higher temperature, which appear more as polyhedrons. Micrographs (backscattered electron imaging, BEI) of cross

(a)

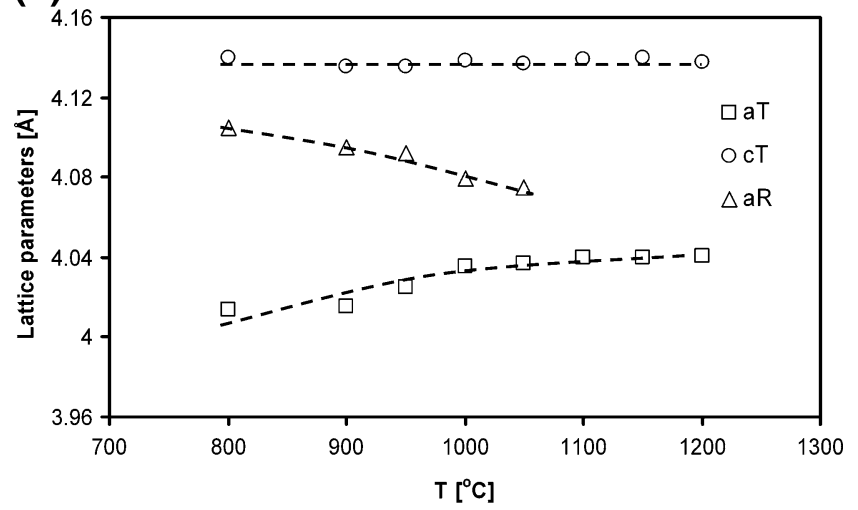

(b)

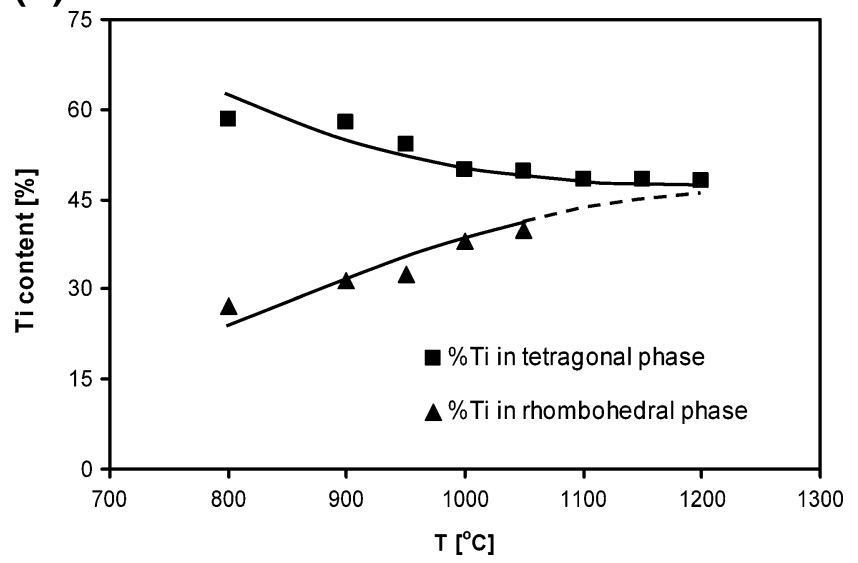

Fig. 2 Average lattice parameters of the tetragonal and rhombohedral phases which are present in the powder as a function of calcining temperature (a). Average Ti content of the tetragonal and rhombohedral phases which are present in the powder as a function of calcining temperature, estimated from the lattice constants of the tetragonal and rhombohedral phases (b). The values of the as received (AR) powder and the powder from the sintered ceramic are plotted at $800^{\circ} \mathrm{C}$ and $1200^{\circ} \mathrm{C}$ respectively 

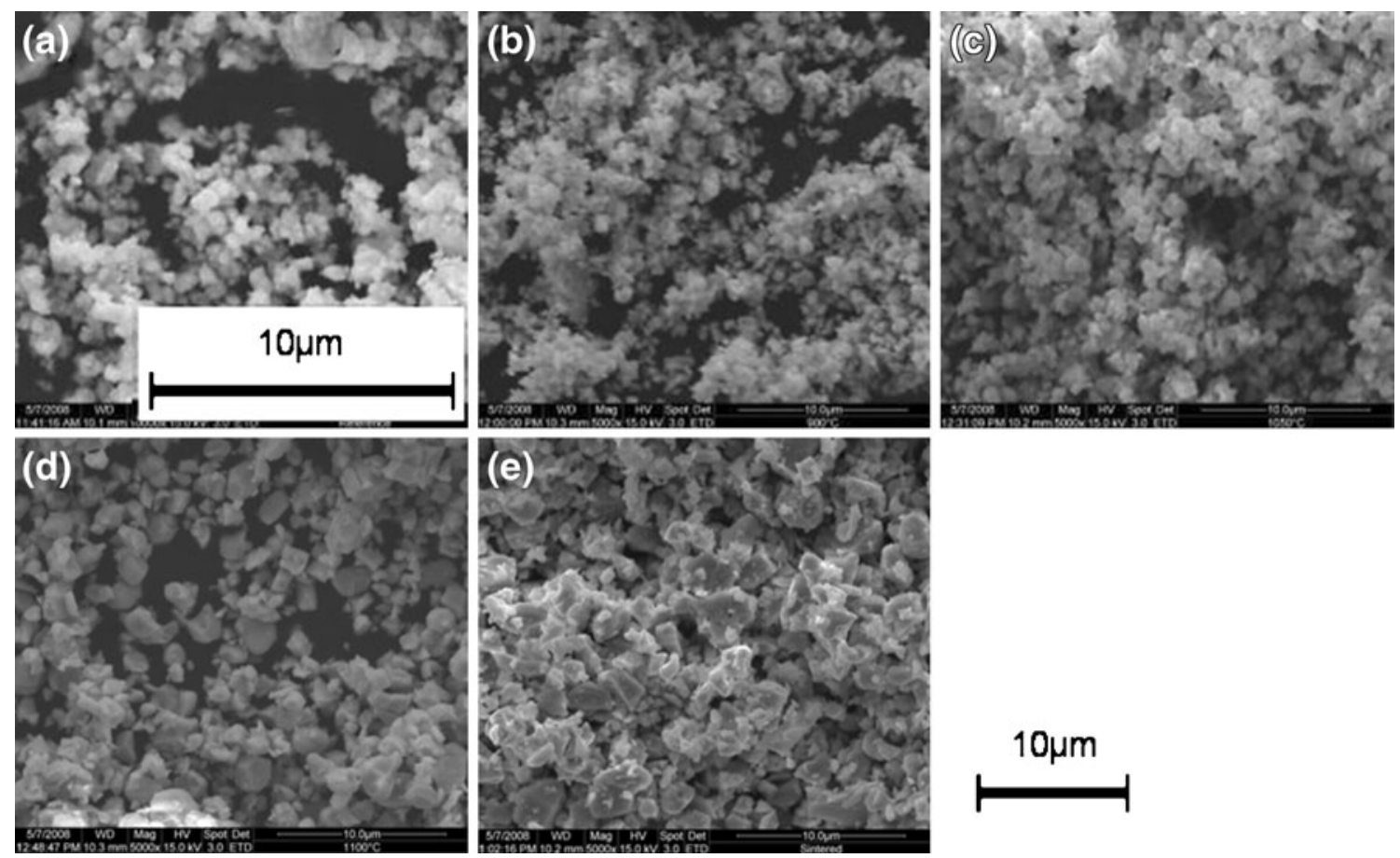

Fig. 3 Micrographs (SEI) of as received PZT powder (a) and powders calcined at $900^{\circ} \mathrm{C} \mathrm{(b),} 1000 \mathrm{C}(\mathbf{c})$ and $1100^{\circ} \mathrm{C}(\mathbf{d})$ and powder obtained from sintered ceramics (e). Note that the as received powder was imaged at a higher magnification (a)

sections of the composites are depicted in Fig. 4. The PZT particles are clearly visible in the SEM micrographs.

From the SEM micrographs of the composite cross sections (Fig. 4) an estimate of the particle sizes of the different powders was made. Using graphical analysis software (ImageJ), the average particle size of the PZT powder was measured by elliptical fitting and by linear intercept method. The particle size was calculated by averaging the data from
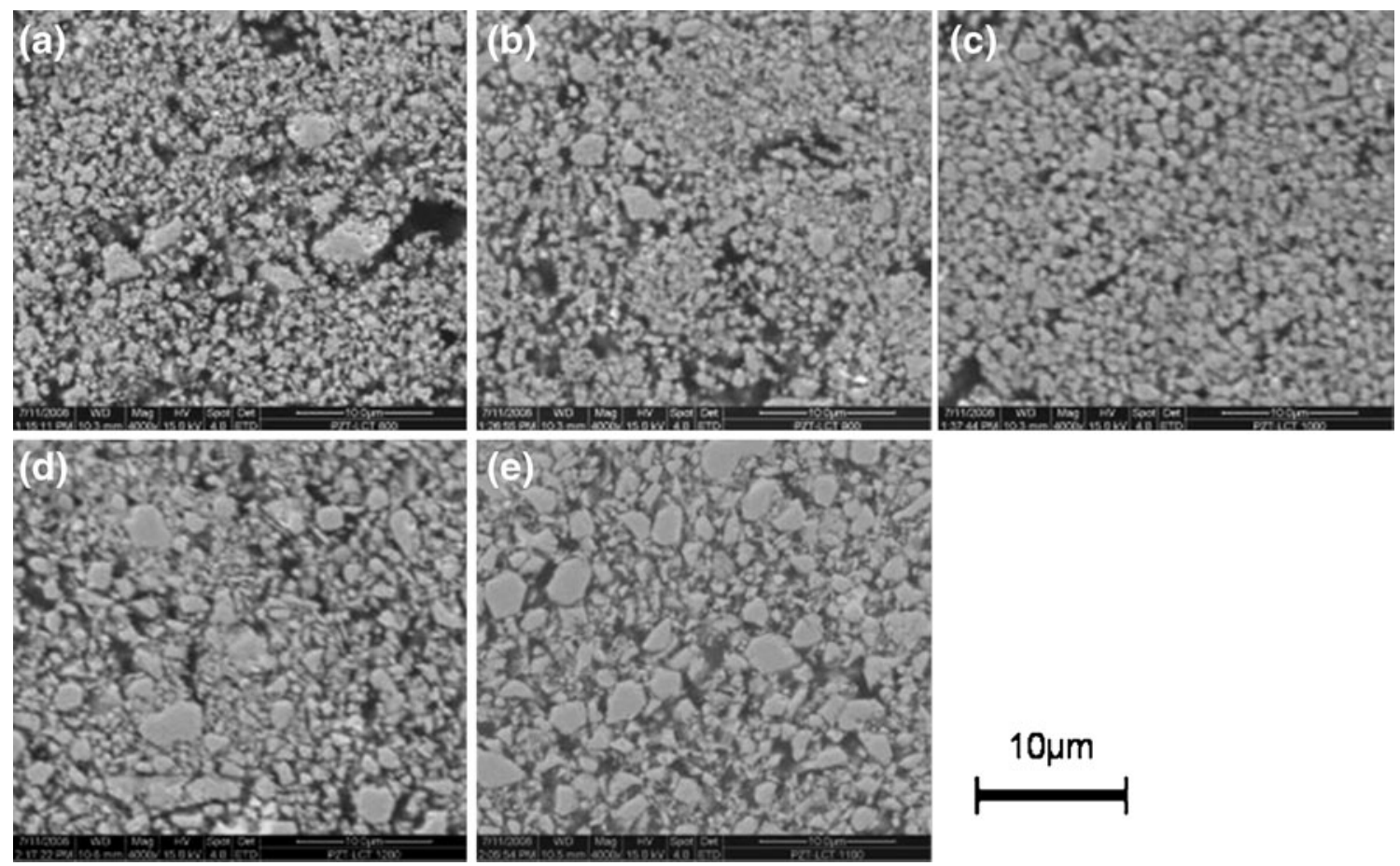

Fig. 4 Micrographs (BEI) of cross sections of PZT-LCT composites containing as received powder (a), powders calcined at $900^{\circ} \mathrm{C}(\mathbf{b}), 1000^{\circ} \mathrm{C}$ (c), $1100^{\circ} \mathrm{C}(\mathbf{d})$ and powder obtained from sintered ceramics (e) 
Table 1 Particle size distribution of the as received (AR) PZT powder, the powders calcined at $900^{\circ} \mathrm{C}, 1000^{\circ} \mathrm{C}$ and $1100^{\circ} \mathrm{C}$ and the powder obtained from sintered ceramics.

\begin{tabular}{lccccc}
\hline & AR & $900^{\circ} \mathrm{C}$ & $1000^{\circ} \mathrm{C}$ & $1100^{\circ} \mathrm{C}$ & Sintered \\
\hline $\mathrm{d}_{10}(\mu \mathrm{m})$ & 0.16 & 0.24 & 0.35 & 0.32 & 0.22 \\
$\mathrm{~d}_{50}(\mu \mathrm{m})$ & 0.64 & 0.68 & 0.87 & 1.04 & 1.18 \\
$\mathrm{~d}_{90}(\mu \mathrm{m})$ & 1.87 & 2.01 & 2.32 & 2.66 & 2.94 \\
\hline
\end{tabular}

both methods (see Table 1). In general, the particle size increases with processing temperature, which is in agreement with literature data [18]. However, for the powders which were calcined at higher temperatures, the fraction of smaller particles increases (i.e. $d_{10}$ decreases). This is an indication that larger particles, which are formed during calcining, are broken up by the ball milling process. This is especially the case in the powder obtained from ball milling the sintered ceramic.

\subsection{Electrical properties}

The dielectric constant $(\varepsilon)$, the measured $d_{33}$ constants and the calculated $g_{33}$ constants of the PZT-LCT composite samples in the poling direction are presented in Fig. 5. All samples were measured before poling and after poling. No change in dielectric constant was measured after poling.

The piezoelectric voltage constant $\left(g_{33}\right)$, which is most important when using the material as a sensor, is dependent on both material properties via the relation:

$g_{33}=\frac{d_{33}}{\varepsilon_{0} \varepsilon_{33}}$.

The calculated $g_{33}$ values are also presented in Fig. 5 . The $g_{33}$ is seen to increase with calcining temperature, as the $d_{33}$ values of the calcined powders increase, but the dielectric constants of the composites remain constant. The $g_{33}$ constant of PZT5A4 ceramics is $28 \mathrm{mVm} / \mathrm{N}$.

\section{Discussion}

When the as received powder is further calcined the phase composition distribution and the grain size of the powder change with calcining temperature and this is of influence on the piezoelectric properties of the powder and therefore also of the composites.

The XRD results indicate that in the as received powder a bimodal distribution of Ti rich tetragonal phases and $\mathrm{Zr}$ rich rhombohedral phases are present, which is not uncommon for powders prepared by the mixed oxide process $[16,17]$. The as received PZT powder is a powder optimised for sintering PZT ceramics, as are most commercially available powders. When commercial sintered ceramics are prepared from these powders homogenisation of the solid solution continues during the final sintering step. This is a slow process, and compositional fluctuations inside the PZT material are known to exist even at temperatures of $1100^{\circ} \mathrm{C}$ in mixed oxide processed ceramics [19].

With the increasing of the calcining temperature, the $\mathrm{PbTiO}_{3}$ phase disappears and the powder contains a bimodal distribution of both rhombohedral and tetragonal $\mathrm{PbZr}_{1-\mathrm{x}} \mathrm{Ti}_{\mathrm{x}} \mathrm{O}_{3}$ phases, corresponding to $\mathrm{Zr}$ rich and Ti rich fractions [16]. With increasing calcining temperature, this mixture of phase fractions will form a more and more homogeneous solid solution, with a $\mathrm{Zr} / \mathrm{Ti}$ ratio equal to that of the starting oxide powders. For the present powder, the final composition is primarily tetragonal. Small fluctuations are possibly still present, but this cannot be accurately determined from the XRD data.

The effect of phase composition distribution changes is analogous to the influence of phase composition of the PZT
Fig. 5 Measured dielectric $(\varepsilon)$ and piezoelectric charge constant $\left(d_{33}\right)$ and calculated piezoelectric voltage constants $\left(g_{33}\right)$ of the PZT-LCT composites containing as received powder, powders calcined at $900^{\circ} \mathrm{C}$ to $1150^{\circ} \mathrm{C}$ and powder obtained from sintered ceramics. The values of the as received (AR) powder and the powder form the sintered ceramic are plotted at $800^{\circ} \mathrm{C}$ and $1200^{\circ} \mathrm{C}$ respectively

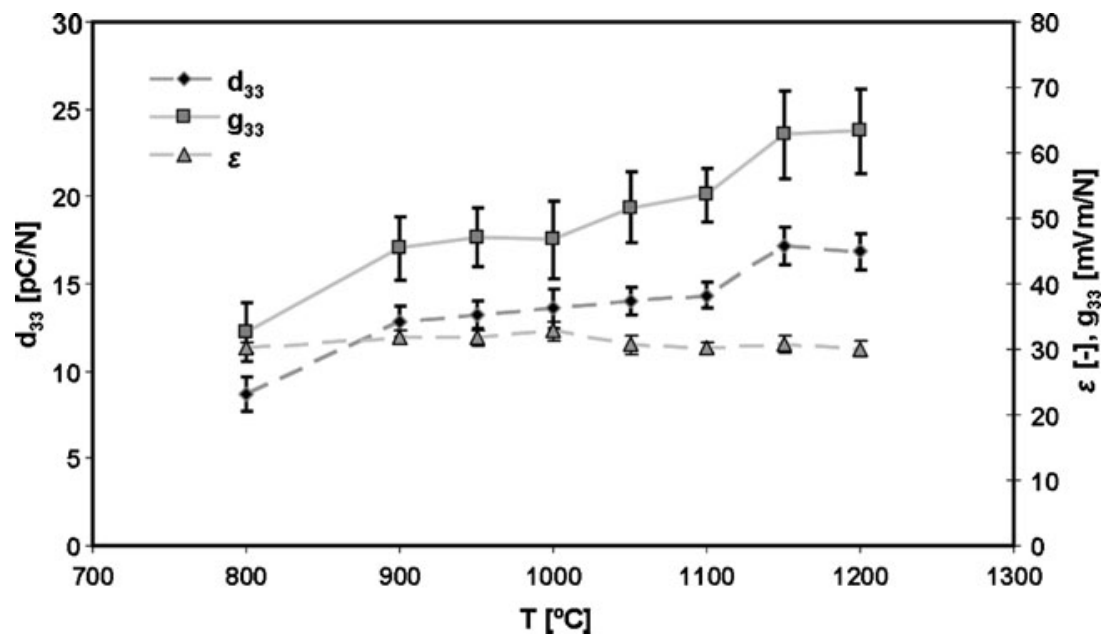


on the piezoelectric properties in the bulk ceramic $[20,21]$ and homogenisation will lead to an increase in particle $d_{33}$. From (undoped) bulk PZT, it is known that the dielectric and piezoelectric constants of PZT increase near the morphotropic phase boundary (MPB). Both constants exhibit a peak at the composition $x=0.48$. When the composition deviates from the MPB compositions, the piezoelectric properties decrease rapidly. Variations of $\Delta x=$ 0.04 on both sides of the MPB have been reported to lead to a loss in $d_{33}$ of as much as $50 \%$ [20]. In PZT powder calcined at low temperatures, the phase fractions with a composition away from the MPB do not contribute much to the piezoelectric activity of the PZT [21]. In this work, compositional deviations from the MPB of much more than $\Delta x=0.04$ are present in low temperature calcined powders (see Fig. 2), which in part explains the low $d_{33}$ of the composites prepared with these powders.

The particle size of the PZT powder also increases with calcining temperature. It is known from piezoelectric ceramics that the grain size of the ceramic influences the ferroelectric behaviour [22] and in nanosized filler particles domain wall pinning and single domain effects reduce the piezoelectric effect considerably [23]. Though the difference in particle sizes was minimized by the ball milling treatment, a difference still exists (see Table 1). In fully homogenous $\mathrm{Nb}$ doped PZT ceramics a $17 \%$ loss of $d_{33}$ is witnessed when grain size is reduced from $2 \mu \mathrm{m}$ to $0.5 \mu \mathrm{m}$ [18], i.e. the range of $\mathrm{d}_{50}$ of the particles in the present study. It is known that the influence of grain size on piezoelectric properties in this size range is larger in sintered ceramics than in powders, as in only ceramics stresses are built up during sintering, which influences the lattice parameters and magnitude of the piezoelectric constants $[18,24]$. Thus, the effect of calcining temperature on the $d_{33}$ coefficient of the particles is a superposition of both phase homogenization and grain size effects, which both lead to higher $d_{33}$ with an increase in calcining temperature.

According to 0-3 composite theory, both dielectric and piezoelectric constants are dominated by the dielectric properties of the polymer matrix $[3,25,26]$. This fact is due to the large dielectric mismatch between the materials and the resulting low electric field component acting on the particles. As a result, a further increase in the PZT dielectric constant will not account for deviations in the composite dielectric properties. However, in many 0-3 piezoelectric models $[3,4]$, the composite $d_{33}$ constant exhibits a linear dependence on the $d_{33}$ constant of the PZT powder. Although severely reduced, a difference in $d_{33}$ of the PZT powder should therefore be measurable in the composite $d_{33}$. Moreover, the dielectric constant of PZT (bulk ceramic) is less dependent on compositional variations than the piezoelectric constant [20]. Correspondingly, no increase is witnessed in the dielectric constant of the composite, though the XRD results indicate homogenisation in the powder (and thus an expected increase in the dielectric constant of the powder). This explains that differences were measured only in $d_{33}$, not necessarily in $\varepsilon$. Therefore, the $g_{33}$ of the composite will also increase with calcining temperature. The composites made with the fully calcined material achieve a $g_{33}$ value, which is almost twice the value of the composite using the as received PZT powder.

\section{Conclusion}

Calcining the PZT powder leads to increased piezoelectric activity in PZT-LCT composites. Higher calcining temperatures lead to higher piezoelectric activity in the composite. This increase in piezoelectric activity corresponds to an increase in homogeneity of the PZT powder. It may also in part be the result of an increase in grain size in the powder. The calcining treatment of the PZT powders roughly doubled both the $d_{33}$ and the $g_{33}$ constant for a composite containing $40 \mathrm{vol} \%$ PZT powder.

Acknowledgements This work was financially supported by the Smartmix funding program (grant SMVA06071), as part of the program "Smart systems based on integrated Piezo". The authors are grateful to Morgan Electro Ceramics (Ruabon, United Kingdom) for providing the PZT powder and PZT5A4 ceramic plates used in this research.

Open Access This article is distributed under the terms of the Creative Commons Attribution Noncommercial License which permits any noncommercial use, distribution, and reproduction in any medium, provided the original author(s) and source are credited.

\section{References}

1. Monnier, T. (2006). J Intel Mat Syst Str, 17, 411

2. Newnham, R. E., Skinner, D. P., \& Cross, L. E. (1978). Mat Res Bull, 13, 525

3. Furukawa, T., Ishida, K., \& Fukada, E. (1979). J Appl Phys, 50, 4904

4. Yamada, T., Ueda, T., \& Kitayama, T. (1982). J Appl Phys, 53, 4328

5. Chan, H. L. W., Chen, Y., \& Choy, C. L. (1995). Ferroelectrics, 9, 207

6. Venkatragavaraj, E., Satish, B., Vinod, P. R., \& Vijaya, M. S. (2001). J PhysD: Appl Phys, 34, 487

7. Satish, B., Sridevi, K., \& Vijaya, M. S. (2002). J. Phys. D Appl. Phys., 35, 2048

8. Senthilkumar, R., Sridevi, K., Venkatesan, J., Annamalai, V., \& Vijaya, M. S. (2005). Ferroelectrics, 325, 121

9. Dietze, M., \& Es-Souni, M. (2008). Sens Actuators A, 143, 329

10. Seema, A., Dayas, K. R., \& Varghese, J. M. (2007). J. Appl. Polymer. Sci., 106, 146

11. Furukawa, T., Fujino, K., \& Fukada, E. (1976). Jpn J Appl Phys, 15,2119

12. Sa-Gong, G., Safari, A., Jang, S. J., \& Newnham, R. E. (1986). Ferroelectrics Lett, 5, 131 
13. Hergenrother, P. M. (2003). High Performance Polymers, 15, 3

14. Knijnenberg, A., Weiser, E. S., Stclair, T. L., Mendes, E., \& Dingemans, T. J. (2006). Macromolecules, 39, 6936

15. van den Ende, D. A., de Almeida, P., \& van de Zwaag, S. (2007). J. Mater. Sci., 42, 6417

16. Hiremath, B. V., Kingon, A., \& Biggers, J. V. (1983). J. Amer. Ceram. Soc, 66, 790

17. Kingon, A. I., Terblanche, P. J., \& Clark, J. B. (1982). Ceram. Int, 8, 108

18. Randall, C. A., Kim, N., Kucera, J. P., Cao, W., \& Shrout, T. R. (1998). J. Amer. Ceram. Soc., 81, 677

19. Kakegawa, K., \& Mohri, J. (1977). Solid State Commun, 24, 769
20. B. Jaffe, W.R. Cook, H. Jaffe, (Academic, New York, 1971) pp. 136. pp. $142-144$

21. Sahoo, B., Jaleel, V. A., \& Panda, P. K. (2006). Mat. Sci. Eng. B, 126,80

22. Kamel, T. M., \& de With, G. (2008). J. Eur. Ceram. Soc., 28, 851

23. Lee, M. H., Halliyal, A., \& Newnham, R. E. (1989). J. Am. Ceram. Soc., 72, 986

24. Helbig, U. (2007). J. Eur. Ceram. Soc., 27, 2567

25. Jayasundere, N., \& Smith, B. V. (1993). J. Appl. Phys., 73, 2462

26. Bruggeman, D. A. G. (1935). Ann. Phys., 24, 636 